\title{
EFFICACY OF SHORT TERM VIDEO EEG IN DETECTING PSYCHOGENIC NON-EPILEPTIC SEIZURES
}

\author{
Sajeesh Parameswaran ${ }^{1}$, Anil Kumar Thankappakurup Vijayamma ${ }^{1}$, Ananthanarayana Marthanda Pillai ${ }^{1}$ \\ Correspondence: psajeesh@gmail.com \\ ${ }^{I}$ Department of Neurosciences Ananthapuri Hospitals and Research Institute, Trivandrum, India.
}

\author{
Article History: \\ Received: October20, 2018 \\ Accepted: February 21, 2019 \\ Published: July 1, 2019 \\ Cite this as: \\ ParameswaranS, Vijayamma \\ AKT, Pillai AM. Efficacy of short \\ term video eeg in detecting \\ psychogenic non-epileptic \\ seizures. Malang Neurology \\ Journal; 2019.5:65-67. DOI: \\ http://dx.doi.org/10.21776/ub.mnj \\ 2019.005.02.3
}

\section{ABSTRACT}

Background:Short term video Electroencephalography (SVEEG) is a non-invasive diagnostic procedure typically last for about 1-5 hours. SVEEG can be utilize to differentiate epileptic from Psychogenic Non-epileptic Seizures (PNES).

Objective:To assess the yield of short term video EEG in detecting PNES.

Methods:Retrospective analysis of short term video EEG in a tertiary level hospital. Patient history, provisional diagnosis, previous EEG and imaging reports were tabulated. Various short term video EEG findings like epileptiform abnormalities, PNES and other non-epileptic events were analyzed in detail. According to the provisional diagnosis formed two groups; Suspecting NEE and suspecting seizure disorders. Change in the provisional diagnosis after SVEEGs were also studied.

Results:A total of 417 SVEEGs analyzed: $34(8.2 \%)$ patients developed events to suggest PNES, $16(3.8 \%)$ patients had other non-epileptic events; $96(23 \%)$ showed interictal epileptiform discharges, $15(3.6 \%)$ showed seizures and 90(21.6\%) patients showed non-specific EEG abnormalities. Around $60 \%$ SVEEGs were conclusive.

Conclusion:A diagnostic event was recorded during SVEEG in majority of patients in the PNES group. SVEEG is a cost effective and useful diagnostic procedure; especially to identify non-epileptic events.

Keywords: PNES, Video EEG, Non epileptic event, Interictal epileptiform discharges, Epilepsy

\section{Introduction}

Psychogenic non-epileptic seizures (PNES) are episodic disturbances of normal functioning and reduced self-control coupled with a range of motor, sensory and mental manifestations that apparentlylook like epileptic seizures, but which are not caused by cortical excitability or epileptic activity. ${ }^{1}$ They are also known as non-epileptic attacks or pseudo or hysterical seizures; most of them fulfill the diagnostic criteria of dissociative or conversion seizure. ${ }^{2}$

The gold standard for the diagnosis of PNES is capturing an attack with typical semiology and lack of epileptic ictal discharges on Video EEG. ${ }^{3}$ Short terms video EEG (SVEEG) is an outpatient procedure; usually lasts about for 1- 5 hours. Many times it is used in the evaluation of PNES. PNES is episode of altered movement, sensation or experience like epileptic seizures, but related with pathopsychological process and not with ictal electrical discharges in the brain. ${ }^{4}$ The prevalence of PNES is equivalent to about $4 \%$ of that of epilepsy. ${ }^{5,6}$ The early detection of PNES is important if delays in the treatment of underlying or associated psychopathology and inappropriate treatment of seizures with antiepileptic drugs are to be avoided. ${ }^{7}$

Some times differentiating PNES from seizures is really tough process because of its psychological etiology and somatic manifestation. Inaccurate diagnosis of epilepsy leads to unnecessary anti-seizure treatment and put needless economic burden on the patients. A comprehensive analysis of semiology and Video EEG may help in early diagnosis of PNES. Simultaneous recording of video of the clinical event and EEG will be supportive to identify non-epileptic events. Prolonged video EEG recording might require admission in the hospital. SVEEG is cost effective than prolonged VEEG for evaluation of non-epileptic events.

The objective of this study was to tabulate various SVEEG findings and assess the efficacy of short term video EEG in detecting PNES.

\section{Methods}

Retrospective analysis of short term video EEG log book, maintained by neuro electrophysiology lab was done. Institute ethics committee has approved the study. All patients who were undergone short term video EEG from June 2012 to June 2017 included. Patient history, provisional diagnosis, previous EEG and imaging reports were tabulated. Digital video EEG was performed by applying internationally accepted 10-20 electrode placement system. Additional EKG and EMG leads connected in all patients. Mean SVEEG recording time was 80 minutes. If spontaneous event was not recorded in suspecting PNES patients, simple suggestion techniques

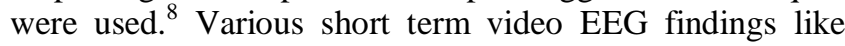
epileptiform abnormalities, non-epileptic events and nonspecific findings studied in detail. According to the 
provisional diagnosis formed two groups; suspecting NEE and suspecting seizure disorders Change in the provisional diagnosis after SVEEGs were also studied.

\section{Results}

A total of 417 SVEEGs analyzed (227 females, 190 males), ranging between 1 year and 80 years (mean 34). Various SVEEG findings were tabulated (Table1). Thirty four (8.2\%) patients developed events to suggest PNES, $16(3.8 \%)$ patients had other non-epileptic events (NEE), 96(23\%) showed interictal epileptiform discharges, 15 (3.6\%) showed seizures and 90(21.6\%) patients showed non-specific EEG abnormalities. Among these patients interictal epileptiform abnormalities consistent with focal epilepsy was identified in $62(14.8 \%)$ patients and primary generalized epilepsy was diagnosed in $34(8.2 \%)$ patients. Around $60 \%$ SVEEGs were found to be conclusive. According to the provisional diagnosis formed two groups;suspecting NEE (108) and suspecting seizure disorder (309). Comparison study of these groups was done (Table 2). In group 1; only one patient showed epileptiform abnormality. But in group 2; out of 309 patients; 5 patients showed non-epileptic events $(\mathrm{p}<0.05)$. Out of 108 patients in group1; 45 patients showed non epileptic events. During non-epileptic events there were no EEG correlate; corresponding EEG showed normal back ground activity ( figure 1a) but during the epileptic seizure corresponding EEG showed ictal rhythm; consisting of rhythmic sharp waves with an evolution in frequency/amplitude (figure 1b).

Table 1.The various short term VEEG findings.

\begin{tabular}{lll}
\hline & $\begin{array}{c}\text { Number } \\
\text { of } \\
\text { patients }\end{array}$ & Percentage \\
\hline PNES & 34 & $8.2 \%$ \\
NEE & 16 & $3.8 \%$ \\
IEDs & 96 & $23 \%$ \\
Non convulsive/convulsive & 15 & $3.6 \%$ \\
seizures & & $21.6 \%$ \\
Non-specific abnormalities & 90 &
\end{tabular}

*PNES-Psychogenic non-epileptic seizures, NEE- other nonepileptic events, IEDs- Interictal epileptiform discharges

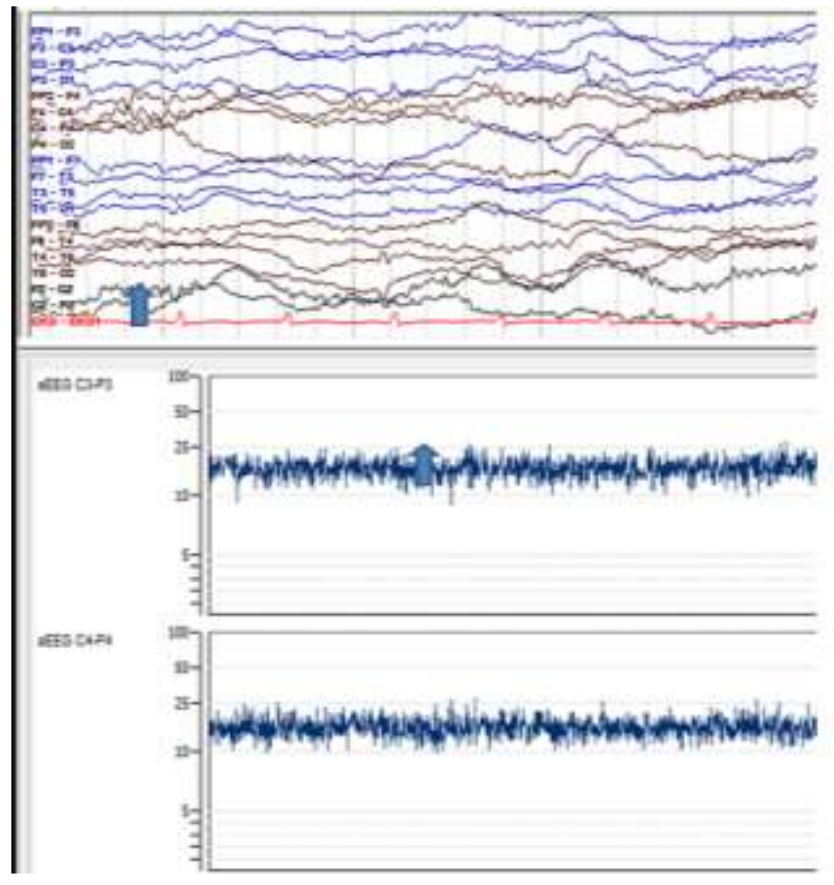

Figure 1a. PNES- with no EEG correlate.

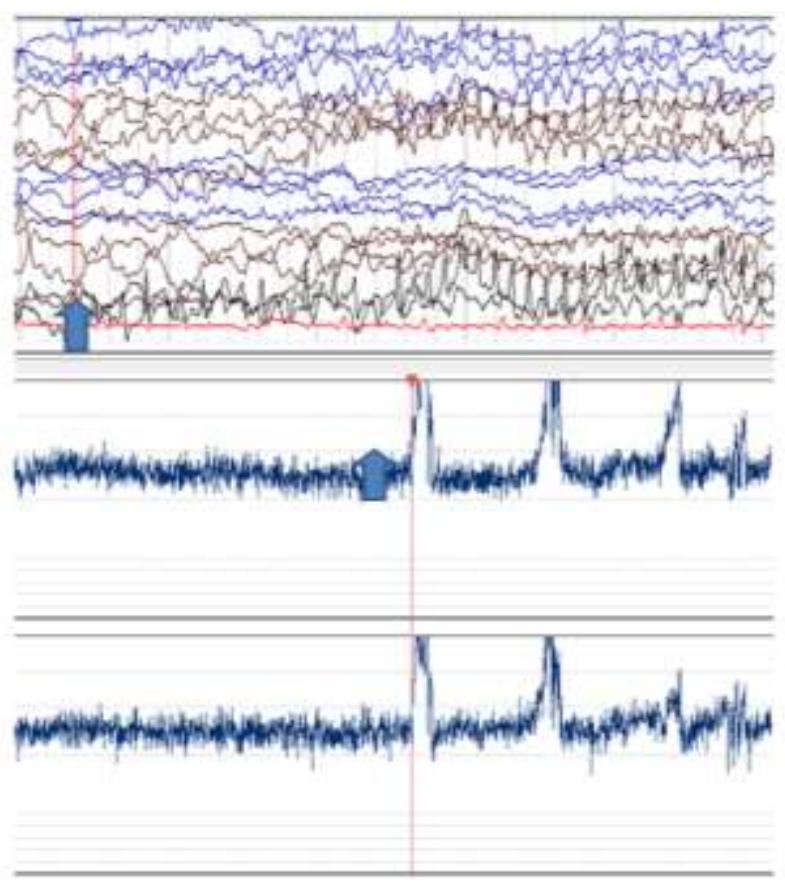

Figure 1b. Seizure: EEG showing ictal rhythm.

Table 2.Comparison study between suspecting NEE and Seizure disorder groups.

\begin{tabular}{llccc}
\hline \multicolumn{1}{c}{ Groups } & NEE/PNES & $\begin{array}{c}\text { Epileptiform } \\
\text { abnormalities }\end{array}$ & $\begin{array}{c}\text { Non-specific } \\
\text { abnormalities }\end{array}$ & Normal \\
NEE & 45 & 1 & 5 & 57 \\
\hline $\begin{array}{l}\text { Seizure } \\
\text { disorder }\end{array}$ & 5 & 110 & 85 & 109 \\
\hline & $*$ Chi square, $\mathrm{p}<0.05$ & &
\end{tabular}

\section{Discussion}

Recording of the typical event with video assisted EEG is considered as a gold standard method in differentiating
PNES and seizure. The diagnosis of non-epileptic events can be hard, and misdiagnosis of epilepsy is common. Distinguishing epileptic seizures from PNES relies on a thorough history from the patient and bystander, but 
recording typical attacks with inpatient video EEG is usually necessary. ${ }^{9}$ H. L. Varela et al stated that habitual PNES can be reliably recorded during short outpatient video EEG in $50 \%$ of adult patients. ${ }^{10}$ However; the clinical usefulness of SVEEG has yet to be determined. In a study among pediatric population; Audrey Riquet et al found that SVEEG was informative and conclusive even in patients with low baseline frequency of clinical events. ${ }^{11}$ Early diagnosis of PNES may improve outcome and evade inappropriate anti-epileptic drug treatment. A means of diagnosing some patients earlier with a readily available and less costly investigation has important clinical and economic implications. ${ }^{12}$ Salinsky et al done study regarding the costs associated with the diagnosis and treatment of PNES. They found that a definite Video EEG confirmed diagnosis of PNES experience considerable reduction in health care utilization. ${ }^{13}$ In a population study done by Scheepers et al found high frequency of misdiagnosis of epilepsy. They found that Forty nine out of 214 patients with a primary diagnosis of epilepsy were subsequently found to have been misdiagnosed following specialist review and investigations. ${ }^{14}$ Only few studies are available in developing countries regarding the efficacy of video EEG in detecting PNES. A study done by Priyanka et al found that short term Video EEG monitoring is very useful in children and events were detected in most of the cases. ${ }^{15}$ Wadwekar et al and Dhimanet al in two different studies observed the semiological features of each PNES episodes in the south Indian population and highlighted the importance of classification. ${ }^{16,17}$ Asadi Pooya et al reported the importance of video EEG in children to establish the diagnosis of PNES. ${ }^{18}$ Rawat et al found that conversion disorder is a common a diagnosis underlying PNES. The study emphasis the importance of multidisciplinary approach in the diagnosis and management of PNES. ${ }^{19}$

Video EEG may helpful to identify PNES and supportive for management. ${ }^{20}$ In a five year retrospective study done by Seneviratne et al found that out patient short term video EEG monitoring has a higher yield of PNES than epilepsy. ${ }^{21}$ PNES often have a unbearable effect on patients' lives. Patients, family members, and clinicians have yet to completely realize the mechanisms and treatment of this disorder. $^{22}$ Health care for PNES could be improved with better education of healthcare professionals and simple diagnostic procedures that do not rely on expensive tests. ${ }^{23}$ Chen Block et al done detail analysis of Video EEG results, clinical characteristics in patients with PNES and prevalence of coexisting epilepsy/PNES in a large cohort. They found that group with PNES only had significantly higher suggestibility and the group with epilepsy/PNES had a significantly higher presence of epilepsy risk factors. ${ }^{24}$

Video EEG monitioring is useful diagnostic procedure and plays central role in the management of patients with epilepsy. A recent study done by Ramanujam et al regarding the use of home videos made on smartphones in PNES evaluation. They found that home videos had sensivity of $95 \%$ but still gold standard is video EEG. ${ }^{25}$ In most of the time patients with PNES will be misdiagnosed having epilepsy and many of them treated with anti epileptic drugs. In our study most of the patients in the nonepileptic group had habitual events to suggest PNES. This establish the role of SVEEG in the PNES evaluation, especially in outpatient settings of developing countries.
One more significant result is that 5 pateints were found to have both epilepsy and PNES; shows overlay of PNES in epileptic patients. We have noticed a female gender predominance among pateints with PNES, but there was no statistical significance. Treatment strategies and patient out comes were not discussed here. However; we are doing a thorough follow up of those patients having PNES.

In the present study we could able to establish the importance of SVEEG in detecting Non-epileptic events; which will be very helpful in treatment strategies. In majority of the patients SVEEG results were conclusive. In epileptic patients we could able to establish the over lay of PNES. So this study is significant also in patients with seizure disorders. The uncontrolled seizure may not always emphasis intractable epilepsy; it could be a non-epileptic event too.

\section{Conclusion}

A definite diagnosis could be reached after short term VEEG in majority of patients. SVEEG is a cost effective and useful diagnostic procedure; especially to identify nonepileptic events.

\section{Acknowledgement}

The author thanks to neuro electrophysiology laboratory of Ananthapuri Hospitals and Research institute, Trivandrum, India for facilitating this research.

\section{References}

1. Brown RJ, Reuber M. Psychological and psychiatric aspects of psychogenic non-epileptic seizures (PNES): a systematic review. Clinical Psychology Review. 2016 Apr 1;45:157-82. DOI: 10.1016/j.cpr.2016.01.003

2. Brown RJ, Syed TU, Benbadis S, LaFrance Jr WC, Reuber M. Psychogenic nonepileptic seizures. Epilepsy \& Behavior; 2011 Sep 1.22(1):85-93. DOI: 10.1016/j.yebeh.2011.02.016

3. LaFrance Jr WC, Baker GA, Duncan R, Goldstein LH, Reuber M. Minimum requirements for the diagnosis of psychogenic non epileptic seizures: a staged approach: a report from the International League Against Epilepsy Nonepileptic Seizures Task Force. Epilepsia; 2013 Nov.54(11): 2005-18. DOI: 10.1111/epi.12356

4. Reuber M, Brown RJ. Understanding psychogenic nonepileptic seizures-phenomenology, semiology and the integrative cognitive model. Seizure; 2017 Jan 1.44:199-205. DOI: 10.1016/j.seizure.2016.10.029

5. Kanemoto K, LaFrance WC, Duncan R, Gigineishvili D, Park SP, Tadokoro Y, Ikeda H, Paul R, Zhou D, Taniguchi G, Kerr M. PNES around the world: where we are now and how we can close the diagnosis and treatment gaps - an ILAE PNES Task Force report. Epilepsia open. 2017 Sep 1;2(3):307-16. DOI: 10.1002/epi4.12060

6. Asadi-Pooya AA, Sperling MR. Epidemiology of psychogenic nonepileptic seizures. Epilepsy \& Behavior; 2015 May 1.46:60-5. DOI: 10.1016/j.yebeh.2015.03.015 
7. Asadi-Pooya AA, Tinker J. Delay in diagnosis of psychogenic nonepileptic seizures in adults: a post hoc study. Epilepsy \& Behavior; 2017 Oct 1.75:1435. DOI: 10.1016/j.yebeh.2017.08.005

8. Popkirov S, Jungilligens J, Grönheit W, Wellmer J. Diagnosing psychogenic nonepileptic seizures: videoEEG monitoring, suggestive seizure induction and diagnostic certainty. Epilepsy \& Behavior; 2017 Aug 1.73:54-8. DOI: 10.1016/j.yebeh.2017.05.027

9. El Tallawy HN, Fukuyama H, Kader AA, Kamel NF, Badry R. Role of short-term out patient video electroencephalography in diagnosis of paroxysmal disorders. Epilepsy research. 2010 Feb 1.88(2-3):17982. DOI: $10.1016 /$ j.eplepsyres.2009.11.001

10. Varela HL, Taylor DS, Benbadis SR. Short-term outpatient EEG-video monitoring with induction in a veterans administration population. Journal of Clinical Neurophysiology; 2007 Oct 1.24(5):390-1. DOI: 10.1097/WNP.0b013e31812f6c11

11. Riquet A, Lamblin MD, Bastos M, Bulteau C, Derambure P, Vallée L, Auvin S. Usefulness of video-EEG monitoring in children. Seizure. 2011 Jan 1;20(1):18-22. DOI.10.1016/j.seizure.2010.09.011

12. Hingray C, El-Hage W, Duncan R, Gigineishvili D, Kanemoto K, LaFrance Jr WC, de Marinis A, Paul R, Pretorius C, Téllez-Zenteno JF, Wiseman H. Access to diagnostic and therapeutic facilities for psychogenic nonepileptic seizures: an international survey by the ILAE PNES Task Force. Epilepsia; 2018 Jan.59(1):203-14. DOI: 10.1111/epi.13952

13. Salinsky M, Storzbach D, Goy E, Kellogg M, Boudreau E. Health care utilization following diagnosis of psychogenic nonepileptic seizures. Epilepsy \& Behavior; 2016 Jul 1.60:107-11. DOI: 10.1016/j.yebeh.2016.04.007

14. Scheepers B, Clough P, Pickles C. The misdiagnosis of epilepsy: findings of a population study. Seizure; 1998 Oct 1.7(5):403-6.PMID: 9808117

15. Madaan P, Gulati S, Chakrabarty B, Sapra S, Sagar R, Mohammad A, Pandey RM, Tripathi M. Clinical spectrum of psychogenic non epileptic seizures in children; an observational study. Seizure. 2018 Jul 1;59:60-6. DOI:10.1016/j.seizure.2018.04.024

16. Wadwekar V, Nair PP, Murgai A, Thirunavukkarasu S, Thazhath HK. Semiologic classification of psychogenic non epileptic seizures (PNES) based on video EEG analysis: Do we need new classification systems?. Seizure; 2014 Mar 31.23(3):222-6. DOI: 10.1016/j.seizure.2013.12.005

17. Dhiman V, Sinha S, Rawat VS, Vijaysagar KJ, Thippeswamy H, Srinath S, Chaturvedi SK, Satishchandra P. Children with psychogenic non- epileptic seizures (PNES): a detailed semiologic analysis and modified new classification. Brain and Development; 2014 Apr 30.36(4):287-93. PMID: 15523134

18. AsadiPooya AA, AlBaradie R, Sawchuk T, Bahrami Z, Al_Amer A, Buchhalter J. Psychogenic non epileptic seizures in children and adolescents: An international cross-cultural study. Epilepsy \& Behavior; 2019 Jan 1.90:90-2. DOI: 10.1016/j.yebeh.2018.11.005

19. Rawat VS, Dhiman V, Sinha S, Sagar KJ, Thippeswamy H, Chaturvedi SK, Srinath S, Satishchandra P. Co-morbidities and outcome of childhood psychogenic non-epileptic seizures-An observational study. Seizure; 2015 Feb 1.25:95-8. DOI:10.1016/j.seizure.2014.09.011

20. Bettini L, Croquelois A, Maeder-Ingvar M, Rossetti AO. Diagnostic yield of short-termvideo-EEG monitoring for epilepsy and PNESs: a European assessment. Epilepsy \& Behavior; 2014 Oct 1.39:558. DOI: 10.1016/j.yebeh.2014.08.009

21. Seneviratne U, Rahman Z, Diamond A, Brusco M. The yield and clinical utility of outpatient short-term video-electroencephalographic monitoring: a fiveyear retrospective study. Epilepsy \& Behavior; 2012 Nov 1.25(3):303-6. DOI: 10.1016/j.yebeh.2012.08.018

22. Jones B, Reuber M, Norman P. Correlates of healthrelated quality of life in adults with psychogenic nonepileptic seizures: A systematic review. Epilepsia; 2016 Feb.57(2):171-81. DOI: 10.1111/epi.13268

23. Hingray C, El-Hage W, Duncan R, Gigineishvili D, Kanemoto K, LaFrance Jr WC, de Marinis A, Paul R, Pretorius C, Téllez-Zenteno JF, Wiseman H. Access to diagnostic and therapeutic facilities for psychogenic nonepileptic seizures: an international survey by the ILAE PNES Task Force. Epilepsia; 2018 Jan.59(1):203-14. DOI: 10.1111/epi.13952

24. Chen-Block S, Abou-Khalil BW, Arain A, Haas KF, Lagrange AH, Gallagher MJ, Azar NJ, Singh P, Sonmezturk HH. Video-EEG results and clinical characteristics in patients with psychogenic nonepileptic spells: The effect of a coexistent epilepsy. Epilepsy \& Behavior; 2016 Sep1.62:62-5. DOI: 10.1016/j.yebeh.2016.06.018

25. Ramanujam B, Dash D, Tripathi M. Can home videos made on smartphones complement video-EEG in diagnosing psychogenic nonepileptic seizures? Seizure. 2018 Nov 1;62:95-8. DOI: 10.1016/j.seizure.2018.10.003 